\title{
Bacterial community characteristics under long-term antibiotic selection pressures
}

\section{Dong Li, Rong Qi, Min Yang*, Yu Zhang, Tao Yu}

State Key Lab of Environmental Aquatic Chemistry, Research Center for Eco-Environmental Sciences, Chinese Academy of Sciences, Beijing 100085, China

\section{A R T I C L E I N F O}

Article history:

Received 25 February 2011

Received in revised form

30 August 2011

Accepted 1 September 2011

Available online 10 September 2011

Keywords:

Antibiotic resistance

Bacterial community

\begin{abstract}
A B S T R A C T
To investigate bacterial community characteristics under long-term antibiotic selection pressures, water samples from the upstream and the downstream sections of two rivers individually receiving the treated penicillin $\mathrm{G}$ and oxytetracycline production wastewater, as well as the anaerobic and the aerobic effluent of the penicillin $G$ production wastewater treatment plant, were taken and analyzed. Antibiotic resistance ratios of bacterial communities in water samples were estimated by culture-based analysis. The majority of bacterial colonies (approximately 55\%-70\%) in both downstream rivers and the aerobic effluent showed resistance to $80 \mu \mathrm{g} / \mathrm{ml}$ of antibiotics tested, while the resistance ratios were less than $10 \%$ and $5 \%$ respectively for both upstream rivers. Six $16 \mathrm{~S}$ rRNA gene clone libraries were constructed with 355 sequences and 215 OTUs totally obtained representing 465 clones. The antibiotic stresses seemed not reduce the diversities of bacterial communities in antibiotic containing water samples compared to those in the two reference upstream rivers. Bacterial groups present in the two reference upstream rivers were common residents in freshwater ecosystems, with the dominant groups as the phyla Proteobacteria including Alphaproteobacteria, Betaproteobacteria and Gammaproteobacteria, as well as Actinobacteria and Bacteroidetes. The phyla Proteobacteria and Firmicutes were dominant in all antibiotic containing water samples, with the clones belonged to Deltaproteobacteria and Epsilonproteobacteria significantly abundant, as well as Gram-positive low GC bacteria in the classes Clostridia and Bacilli. It thus seemed that Deltaproteobacteria, Epsilonproteobacteria, Clostridia and Bacilli might be specifically associated with antibiotic containing environments.
\end{abstract}

(c) 2011 Elsevier Ltd. All rights reserved.

\section{Introduction}

Environments containing high concentrations of antibiotics are normally anthropogenic, such as municipal, hospital, stock raising and pharmaceutical producing wastewater, as well as polluted surface water and fishery ponds. Antibiotics in these aquatic environments could directly act on bacterial strains and exert selective pressure, resulting in the change of bacterial community structure inevitably. However, little is known about the taxonomic composition of the whole bacterial community in antibiotic polluted environments. Although numerous researches have been performed to investigate antibiotic resistance characteristics of bacterial isolates from different environmental sources including stock farms, poultry farms, fisheries, surface water, and lakes (Wittwer et al., 2005; Huddleston et al., 2006; Jindal et al., 2006;

\footnotetext{
* Corresponding author. Tel./fax: +86 1062923475.

E-mail address: yangmin@rcees.ac.cn (M. Yang). 
Hamelin et al., 2007), most of these researches were focused on human related pathogens (Huddleston et al., 2006; Hamelin et al., 2007), and the remaining generally isolated environmental bacteria using non-selective rich nutrient media at aerobic conditions (Miranda and Zemelman, 2002; Messi et al., 2005). Gammaproteobacteria like Pseudomonas spp. was generally the dominant bacterial group in these culture-based studies, mainly due to the favored growth of Gammaproteobacteria in nutrient rich culture media. Several other bacterial groups such as Bacteroidetes, Actinobacteria, Betaproteobacteria and Alphaproteobacteria were also recovered with comparably lower colony numbers. As the majority of bacterial species in environments still could not be isolated and cultured, the above culture-based researches could not reflect the actual composition of the whole community. Some particular bacterial groups which are difficult to be cultured at normal conditions might be dominant in environments containing antibiotics.

Furthermore, under the selection pressure of antibiotics, most of bacterial strains might become resistant to antibiotics. Some metagenomic researches have demonstrated that the diversity of antibiotic resistance genes in environments is greater than previously accounted for basing on cultured bacteria, indicating that many resistance genes are actually carried by uncultured bacteria (Riesenfeld et al., 2004; D'Costa et al., 2006; Sommer et al., 2009). The whole bacterial community including both cultured and uncultured bacteria constitutes an important reservoir of antibiotic resistance genes which could furthermore move into pathogens via horizontal gene transfer facilitated with mobile gene elements such as plasmids, transposons and so on (Thomas and Nielsen, 2005), as confirmed by numerous investigations about antibiotic resistant pathogenic bacteria (Martínez et al., 2007). The elucidation of bacterial community composition in antibiotic containing environments would thus help to suggest the potential antibiotic resistant bacterial groups, which might be important carriers of resistance genes and sometimes the source of clinically important resistance genes (Martínez, 2008).

To our knowledge, few researches have been performed to elucidate the whole bacterial community structures in antibiotic containing environments until now. Córdova-Kreylos and Scow have elucidated the effects of ciprofloxacin on salt marsh sediment microbial communities by using phospholipid fatty acid (PLFA) analysis (Córdova-Kreylos and Scow, 2007). However, their conclusions were acquired through lab-experiment, which might not be able to reflect the situations in actual environments. Thus in this study, two rivers individually receiving the treated penicillin $G$ and oxytetracycline production wastewater, which were discharged from two antibiotic producing facilities and both contained significantly higher concentrations of antibiotics than normal aquatic environments ( $\mathrm{Li}$ et al., 2008a,b), were selected to investigate bacterial community characteristics under longterm antibiotic stresses. Considering that many environmental factors might influence bacterial community structures, several water samples from the penicillin $G$ production wastewater treatment facility were also obtained and analyzed to compare with river samples. The antibiotic resistance ratios of bacterial communities in water samples were first estimated using culture-based analysis. Clone libraries of $16 \mathrm{~S}$ rRNA gene which could provide the detailed and reliable information were then constructed for water samples from each site. The results would help to complement existing knowledge of bacterial community composition in antibiotic containing environments and suggest the possible environmental antibiotic resistant groups still unknown until now.

\section{Materials and methods}

\subsection{Study site and sampling}

The two rivers and wastewater treatment plants (WWTPs) were all located in Hebei Province, China. Penicillin G production wastewater is treated in the WWTP which included an anaerobic digestion, a hydrolyzation and two aerobic reactors successively. The treated effluent is discharged into the receiving river, Wangyang River. Meanwhile, the production wastewater from another oxytetracycline producing facility is treated in the WWTP including a sequence batch reactor and a continuous-flow activated sludge reactor, and then discharged into the Xiao River. In December 2004, April and August 2005, surface water samples from upstream (longitude $114^{\circ} 42^{\prime} 13^{\prime \prime} \mathrm{E}$ and latitude $37^{\circ} 59^{\prime} 8^{\prime \prime} \mathrm{N}$ for Wangyang River; longitude $114^{\circ} 27^{\prime} 19^{\prime \prime} \mathrm{E}$ and latitude $38^{\circ}$ $2^{\prime} 4^{\prime \prime} \mathrm{N}$ for Xiao River) and downstream sections (longitude $114^{\circ} 53^{\prime} 20^{\prime \prime} \mathrm{E}$ and latitude $37^{\circ} 52^{\prime} 38^{\prime \prime} \mathrm{N}$ for Wangyang River; longitude $114^{\circ} 34^{\prime} 39^{\prime \prime} \mathrm{E}$ and latitude $37^{\circ} 51^{\prime} 50^{\prime \prime} \mathrm{N}$ for Xiao River) of wastewater discharging points, as well as the effluent samples from the anaerobic and aerobic apartments of the penicillin $G$ production wastewater treatment plant were all taken in 4- $\mathrm{L}$ brown glass bottles. Water samples were kept at $4{ }^{\circ} \mathrm{C}$ in the darkness for at most two days. Upstream and downstream sampling sites were individually approximately $5 \mathrm{~km}$ and $30 \mathrm{~km}$ away from the discharging point at the Wangyang River, and $5 \mathrm{~km}$ and $20 \mathrm{~km}$ away at the Xiao River. Penicillin G and oxytetracycline residues in water samples were all determined using LC-ESI-MS. The detailed analysis methods and the characteristics of water samples could be found elsewhere (Li et al., 2008a,b).

\subsection{Culture-based analysis}

Water samples from the upstream and downstream sections of the two rivers, as well as the aerobic effluent of the penicillin $\mathrm{G}$ production wastewater treatment plant were applied for culture-based analysis. Two sets of plates were simultaneously incubated for each water sample at proper dilution using non-selective Tryptic soy agar (TSA) at $30^{\circ} \mathrm{C}$ for $24 \mathrm{~h}$ aerobically. Control plate was not added with any antibiotics, then $80 \mu \mathrm{g} / \mathrm{ml}$ ampicillin was added in agar for the upstream and downstream water samples of penicillin $G$ containing river, as well as the aerobic effluent, and $80 \mu \mathrm{g} / \mathrm{ml}$ oxytetracycline was added for the upstream and downstream water samples of oxytetracycline containing river. Ampicillin was used instead of penicillin $\mathrm{G}$ due to its broad-spectrum ability. The percentages of the colony numbers of plates added with antibiotics accounting for those of the corresponding control 
Table 1 - Distribution of phylogenetic groups among bacterial 16S rRNA gene clone libraries for the upstream and

downstream of the two rivers individually receiving treated penicillin $G$ and oxytetracycline production wastewater, as well as the anaerobic and the aerobic effluent of penicillin $\mathbf{G}$ production wastewater.

\begin{tabular}{|c|c|c|c|c|c|c|c|}
\hline \multirow[t]{2}{*}{ Phylum } & \multirow[t]{2}{*}{ Class } & \multicolumn{6}{|c|}{ No. of OTUs (no. of clones) } \\
\hline & & $\begin{array}{l}\text { Upstream } \\
{\text { river } 1^{\mathrm{a}}}^{\text {a }}\end{array}$ & $\begin{array}{l}\text { Upstream } \\
\text { river }^{\mathrm{b}}\end{array}$ & $\begin{array}{l}\text { Downstream } \\
\text { river1 }^{\mathrm{a}}\end{array}$ & $\begin{array}{l}\text { Downstream } \\
{\text { river } 2^{\mathrm{b}}}\end{array}$ & $\begin{array}{l}\text { Anaerobic } \\
\text { effluent }\end{array}$ & $\begin{array}{l}\text { Aerobic } \\
\text { effluent }\end{array}$ \\
\hline \multirow[t]{6}{*}{ Proteobacteria } & Alpha- & $5(12)$ & $9(13)$ & $5(6)$ & $3(3)$ & $1(1)$ & $1(1)$ \\
\hline & Beta- & $3(13)$ & $10(32)$ & $9(15)$ & $3(6)$ & $1(2)$ & $13(18)$ \\
\hline & Gamma- & $2(9)$ & $2(3)$ & $1(2)$ & $1(2)$ & - & - \\
\hline & Delta- & - & - & $5(10)$ & $6(12)$ & $2(8)$ & $5(9)$ \\
\hline & Epsilon- & - & - & $1(3)$ & $3(19)$ & $5(11)$ & $5(13)$ \\
\hline & Unclassified & - & $1(1)$ & - & $1(1)$ & - & $1(3)$ \\
\hline \multirow[t]{3}{*}{ Firmicutes } & Clostridia & $1(1)$ & - & $8(20)$ & $9(12)$ & $12(43)$ & $2(3)$ \\
\hline & Bacilli & $1(5)$ & - & $3(10)$ & $1(5)$ & $3(7)$ & $5(18)$ \\
\hline & Unclassified & - & - & $2(2)$ & - & $1(4)$ & $1(2)$ \\
\hline Actinobacteria & Actinobacteria & $7(24)$ & $1(3)$ & $2(3)$ & $1(2)$ & - & - \\
\hline Planctomycetes & Planctomycetacia & $1(3)$ & $2(3)$ & - & - & - & $2(2)$ \\
\hline Acidobacteria & Acidobacteria & $1(6)$ & $3(3)$ & $2(2)$ & - & - & - \\
\hline \multirow[t]{4}{*}{ Bacteroidetes } & Bacteroidetes & - & $1(1)$ & $1(1)$ & $3(6)$ & - & $2(3)$ \\
\hline & Flavobacteria & - & $2(5)$ & $1(2)$ & - & - & - \\
\hline & Sphingobacteria & $1(1)$ & $5(5)$ & $1(1)$ & - & - & $1(1)$ \\
\hline & Unclassified & - & $1(1)$ & $1(2)$ & $3(3)$ & - & $1(3)$ \\
\hline \multirow[t]{2}{*}{ Chloroflexi } & Anaerolineae & - & - & - & - & - & $1(1)$ \\
\hline & Unclassified & - & - & - & - & - & $1(1)$ \\
\hline Gemmatimonadetes & Gemmatimonadetes & - & - & $1(1)$ & - & - & - \\
\hline Verrucomicrobia & Verrucomicrobiae & - & $1(1)$ & - & $1(1)$ & - & - \\
\hline Lentisphaerae & Lentisphaerae & - & - & - & $1(1)$ & - & - \\
\hline Unclassified & & $1(1)$ & $1(2)$ & $2(2)$ & $3(4)$ & $1(1)$ & $3(3)$ \\
\hline Total no. & & $23(75)$ & $39(73)$ & $45(82)$ & $39(77)$ & $26(77)$ & $43(81)$ \\
\hline
\end{tabular}

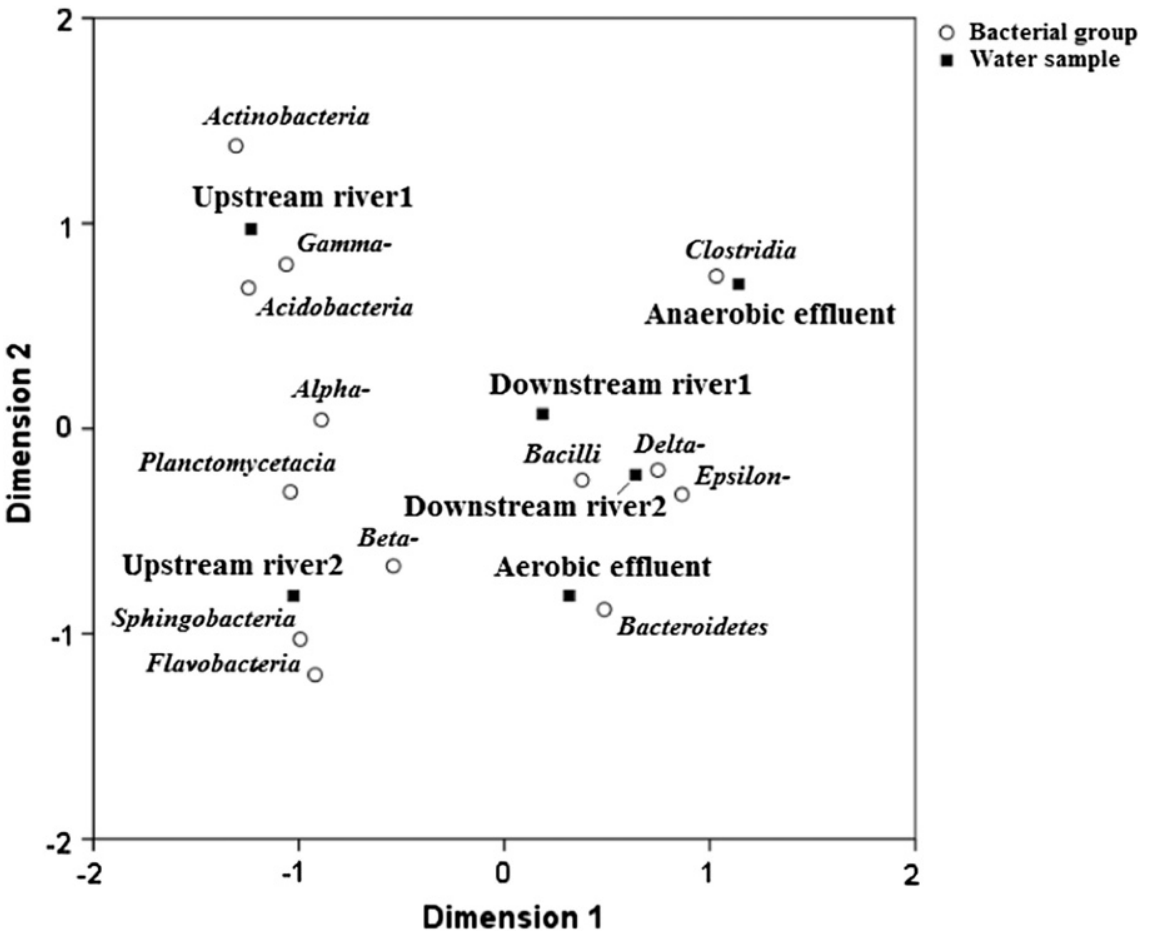

Fig. 1 - Multiple correspondence analysis of bacterial groups and water samples including upstream and downstream of the two rivers 1 and 2 individually receiving treated penicillin $\mathrm{G}$ and oxytetracycline production wastewater, as well as the anaerobic and the aerobic effluent of penicillin $\mathrm{G}$ production wastewater. Only bacterial groups with sufficient sample sizes were shown. 


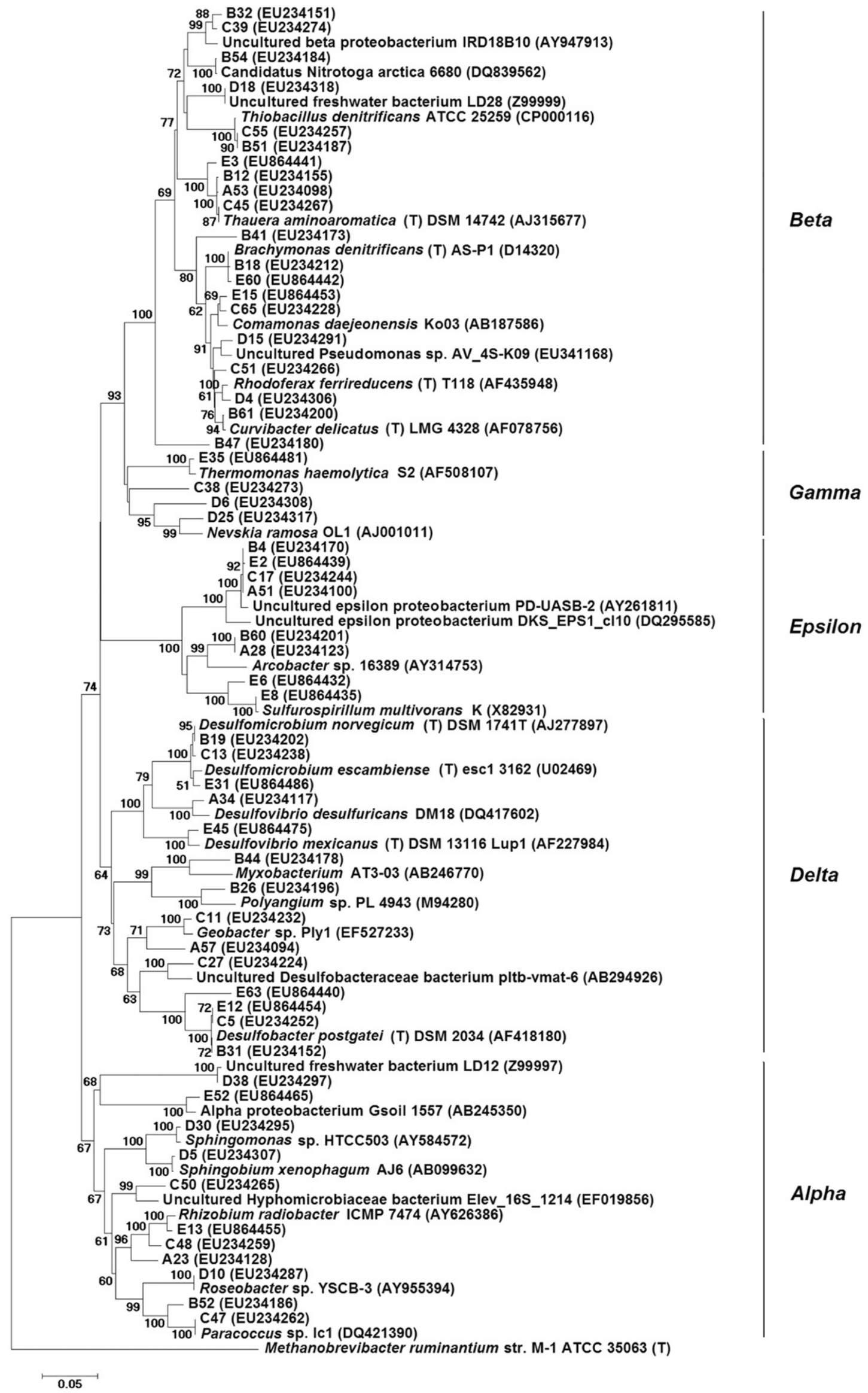


plates were used to reflect antibiotic resistance ratios of bacterial community in water samples.

\subsection{DNA extraction, PCR, cloning and sequencing of $16 \mathrm{~S}$ rRNA genes}

500-ml water sample was vacuum filtered through a $0.2-\mu \mathrm{m}$ pore-size polyethersulfone membrane filter. Then samples were washed by $10 \mathrm{ml}$ of phosphate buffer (pH 8.0), and DNA was extracted using the cetyltrimethylammonium bromide (CTAB) method as described previously (Crump et al., 1999). The yield and quality of DNA was estimated visually after electrophoresis on $1 \%$ (wt/vol) agarose gel through comparison with a molecular mass ladder.

The 16S rRNA gene was amplified using bacteria universal primers 27F (5'-AGAGTTTGATCCTGGCTCAG) and 1492R (5'TACGGYTACCTTGTTACGACTT) (Lane, 1991). The standard $50 \mu \mathrm{l}$ PCR mixture (Takara, Dalian, China) included $1 \times$ PCR buffer containing $1.5 \mathrm{mM} \mathrm{MgCl} 2,200 \mu \mathrm{M}$ of each deoxynucleoside triphosphate, $10 \mathrm{pmol}$ of each primer, $1.25 \mathrm{U}$ of TaKaRa rTaq polymerase, and approximately $50 \mathrm{ng}$ of template DNA. PCR conditions were as follows: $95{ }^{\circ} \mathrm{C}$ for $10 \mathrm{~min}$, followed by 30 cycles of $95^{\circ} \mathrm{C}$ for $1 \mathrm{~min}, 55^{\circ} \mathrm{C}$ for $1 \mathrm{~min}$, and $72{ }^{\circ} \mathrm{C}$ for $1 \mathrm{~min} 30 \mathrm{~s}$, and a final extension at $72{ }^{\circ} \mathrm{C}$ for $15 \mathrm{~min}$. After confirmed by electrophoresis in 1.2\% (wt/vol) agarose gel, amplification products were purified with the Qiaquick PCR cleanup kit (Qiagen, Inc., Chatsworth, Calif.). In order to minimize PCR bias in subsequent cloning steps, three separate reactions were run for each sample and pooled together, PCR products of the samples from the same sampling site was also pooled together.

The amplified 16S rRNA gene products were further cloned into the TOPO TA cloning vector PCR2.1, and TOP10 E. coli transformants were further selected according to manufacture's instructions (Invitrogen). Cloned inserts were amplified from lysed colonies by PCR with plasmid-vector specific primers M13F and M13R under the same conditions with above. PCR products were digested $\left(3 \mathrm{~h}, 37^{\circ} \mathrm{C}\right)$ with HaeIII (Takara, Dalian, China) and separated by electrophoresis through $2 \%$ agarose gels. Clones were grouped based on RFLP patterns, and representative clones were sequenced with an ABI 3730 automated sequencer (Invitrogen, Shanghai, China).

\subsection{Phylogenetic and statistical analysis}

DNA sequences were edited manually using BioEdit (Hall, 1999), and then searched against RDP II and the GenBank database (Altschul et al., 1997; Cole et al., 2007). The most similar reference sequences were retrieved and aligned with clone sequences using ClustalX (Thompson et al., 1997). Phylogenetic trees were constructed using MEGA, version 3.1 by the neighbor-joining algorithm and the Jukes-Cantor distance estimation method (Kumar et al., 2004). Possible chimeras were checked using CHIMERA_CHECK in RDP II.

The sequences sharing $97 \%$ or greater similarity were grouped into the same operational taxonomic unit (OTU) and the OTU number was determined using DOTUR (Schloss and Handelsman, 2005). OTU richness $S_{\text {Chao1 }}$ and $S_{A C E}$ as well as Shannon diversity $(H)$ were calculated using EstimateS version 8.0 with 100 random sample repetitions (Colwell, 2005). Evenness $(E)$ indices were calculated as follows: $E=H / l n n$, where $n$ is OTU number. Coverage $(C)$ was calculated as follows: $C=1-$ $\left(n_{1} / N\right)$, where $n_{1}$ is the number of OTUs that occurred once and $\mathrm{N}$ is the total number of clones. Rarefaction curves were constructed using aRarefactWin (http://www.uga.edu/ strata/ software.html). UniFrac computational analysis was performed to compare clone libraries from different sampling sites (Lozupone and Knight, 2005). Clone libraries from different sites were clustered by the application of the UPGMA method to the UniFrac metric matrix, and principal coordinate analysis (PCoA) was also performed with UniFrac metric matrix. Multiple correspondence analysis of specific bacterial groups with a sufficient sample size ( 5 or more clones) and water samples was also performed by using the SPSS version 16.0 release.

\subsection{Nucleotide sequence accession numbers}

The 16S rRNA gene sequences could be accessed in the GenBank database under the accession numbers EU234086 to EU234324, EU864431 to EU864494 and FJ230892-FJ230941.

\section{Results}

\subsection{Antibiotics and resistance ratios in water samples}

The concentrations of penicillin $G$ decreased from $72.6 \pm 3.7 \mu \mathrm{g} / \mathrm{L}$ in the anaerobic effluent to $1.68 \pm 0.48 \mu \mathrm{g} / \mathrm{L}$ in the aerobic effluent of the WWTP, and ranged from $0.35 \mu \mathrm{g} / \mathrm{L}$ to under the detection limit $(0.031 \mu \mathrm{g} / \mathrm{L})$ in the receiving river water samples (Li et al., 2008b). Meanwhile, oxytetracycline was determined in the downstream of Xiao River at $376.7 \pm 141.7 \mu \mathrm{g} / \mathrm{L}$ (Li et al., 2008a). No penicillin G or oxytetracycline could be detected in the reference upstream rivers. The antibiotic residual levels in this study were comparably much higher than those reported in normal aquatic environments previously (Kolpin et al., 2002).

Antibiotic resistance ratios were roughly estimated for all the river water and the aerobic effluent samples using culturebased resistance assay. Approximately $65 \%$ of colonies from penicillin G containing downstream water and $70 \%$ of the aerobic effluent colonies showed resistance to $80 \mu \mathrm{g} / \mathrm{ml}$ of ampicillin, with the resistance percentages less than $10 \%$ for the reference upstream river. Then approximately $55 \%$ of colonies from the oxytetracycline containing downstream

Fig. 2 - Phylogenetic relationships of representative bacterial 16S rRNA gene sequences within the phylum Proteobacteria from clone libraries of this study determined by the neighbor-joining method. Bootstrap values of $>50 \%$ (obtained with 1000 resamplings) are shown at nodes. The scale bar indicates 0.05 nucleotide substitution per site. The reference sequences are obtained from the Ribosomal Database Project II or GenBank. Methanobrevibacter ruminantium is used as an outgroup. GenBank accession numbers are in parentheses. 
river showed resistance to $80 \mu \mathrm{g} / \mathrm{ml}$ of oxytetracycline, while the resistance ratio was less than $5 \%$ in the reference upstream river. The significant difference of resistance ratios between the antibiotic containing water samples and the reference upstream river samples indicated that the concentrations of penicillin $G$ and oxytetracycline residues in the polluted rivers and wastewater were high enough for leading most of the bacteria population in water samples resistant to antibiotics, in addition with the fact that the concentrations of $80 \mu \mathrm{g} / \mathrm{ml}$ of antibiotics tested in this study were much higher than the relevant breakpoints recommended by CLSI Standards guidelines (Clinical and Laboratory Standards Institute, 2003). The CFU number of ampicillin resistant bacteria was $3.4 \times 10^{4} \mathrm{cfu} / \mathrm{ml}$ in penicillin $\mathrm{G}$ containing downstream water, $4.8 \times 10^{4} \mathrm{cfu} / \mathrm{ml}$ in the aerobic effluent, and less than $8.9 \times 10^{2} \mathrm{cfu} / \mathrm{ml}$ in the reference upstream river water. Meanwhile the CFU number of oxytetracycline resistant bacteria in the oxytetracycline containing downstream river was $7.7 \times 10^{2} \mathrm{cfu} / \mathrm{ml}$, and less than $1 \times 10^{2} \mathrm{cfu} / \mathrm{ml}$ in the reference upstream river.

\subsection{S rRNA clone libraries and statistical analysis}

Six clone libraries were individually constructed for the upstream and downstream water samples of both rivers, as well as the anaerobic and aerobic effluent of the WWTP for treating penicillin G production wastewater. Total of 355 sequences were obtained and grouped into 215 OTUs, representing 465 clones derived from the six clone libraries of this study (Table 1). Possible chimeras were discarded.

Several unique characteristics of the bacterial communities were observed for all antibiotics containing water samples, including both downstream rivers as well as the anaerobic and aerobic effluent, as illustrated in Fig. 1, of which dimension 1 explained $52.9 \%$ of the observed variation, and dimension 2 explained $21.3 \%$ of the variation. The most notable characteristics were the abundance of clones belonging to the deeply rooting classes Deltaproteobacteria and Epsilonproteobacteria, the total of which individually representing $15.9 \%$ and $40.3 \%$ of the clone numbers of the libraries for the penicillin $\mathrm{G}$ and oxytetracycline polluted downstream rivers, and accounting for $24.7 \%$ and $27.2 \%$ of the clones in the anaerobic and aerobic effluent libraries, respectively (Table 1). The clones grouped into Deltaproteobacteria in all antibiotic containing samples were mainly classified as Desulfovibrio spp., Desulfovibrio mexicanus, Desulfovibrio desulfuricans, Desulfobacter spp., Desulfobacter postgatei, Desulfomicrobium norvegicum, Desulfomicrobium escambiense, and Desulfomicrobium apsheronum (Fig. 2), all of which were sulfate- or sulfurreducing bacteria. These species are generally strictly anaerobic and gain energy by coupling the complete or partial oxidation of organic compounds or molecular hydrogen to the reduction of sulfur or sulfate generating hydrogen sulfide. Then all clones in the class Epsilonproteobacteria were classified into the genera Sulfurouum, Sulfurospirillum and Arcobacter, all of which are sulfur and hydrogen sulfide- or thiosulfateoxidizing bacteria, with nitrate or oxygen as electron acceptors.

Additionally, the phylum Firmicutes including the classes Clostridia and Bacilli, both of which were Gram-positive low GC bacteria, had become the second abundant bacterial group comprising of $39.0 \%$ and $22.1 \%$ of the clones in the libraries for penicillin $\mathrm{G}$ and oxytetracycline polluted downstream rivers, respectively (Table 1). Meanwhile, the clones belonged to Clostridia and Bacilli were dominant in the anaerobic effluent library, and more or less as abundant as those belonging to Proteobacteria in the aerobic effluent library. The Bacilli clones in all these antibiotic containing water samples were further classified into the genera Trichococcus and Streptococcus, of which Trichococcus spp., especially Trichococcus flocculiformis were the dominant species among the Bacilli clones and appeared in almost all antibiotic containing samples (Fig. 3). T. flocculiformis is an aerotolerant, fermentative organism, and originally isolated from bulking sludge in Germany (Scheff et al., 1984). Furthermore, the majority of the clones (46.2\%) in the class Clostridia have been classified into Mitsuokella spp. including Mitsuokella multacida. M. multacida was generally anaerobic rumen bacteria with phytase activity and was belonged to the Sporomusa subbranch of low GC Gram-positive bacteria. The remaining clones in the Clostridia were mainly affiliated with the anaerobic genera Aminobacterium, Desulfosporosinus, Anaerovorax, Acetobacterium, Mogibacterium, Dialister, Clostridium, Thermoanaerobacterium and Ruminococcus. Several genera were spore forming bacteria, such as Desulfosporosinus, Clostridium and Thermoanaerobacterium.

The similarities of OTUs among all the antibiotic containing environments were determined using software DOTUR. Totally, 13 OTUs were shared by the bacterial community libraries of the penicillin $\mathrm{G}$ polluted downstream river and the two penicillin wastewater samples, and 7 OTUs were shared by those of the oxytetracycline polluted downstream river and the two penicillin wastewater samples. Then 5 OTUs were shared by those of the two antibiotic containing downstream rivers, and 4 OTUs were shared by the two wastewater libraries. Two OTUs were furthermore shared across all antibiotic containing aquatic environments. Most of these OTUs fell into Deltaproteobacteria, Epsilonproteobacteria, Clostridia and Bacilli, also suggesting that these bacterial groups might be specifically associated with antibiotic containing aquatic environments at both species and classes levels. Several other bacterial groups seemed also to be related to the antibiotic containing aquatic environments, such as the class Bacteroidetes, as well as the phyla Chloroflexi, Gemmatimonadetes, and Lentisphaerae (Fig. 1 and Table 1). However, as few clones were obtained for these bacterial groups and distributed dispersedly in wastewater and downstream river samples, no more confirmative relationships could be drawn between these bacterial groups and antibiotic containing environments.

The bacterial community compositions in the two reference upstream river samples were also analyzed using clone libraries. Bacterial groups present were common residents in freshwater ecosystems, with the dominant groups as the phyla Proteobacteria including Alphaproteobacteria, Betaproteobacteria and Gammaproteobacteria, as well as Actinobacteria and Bacteroidetes (Table 1). The remaining clones were classified into the phyla Planctomycetes, Acidobacteria, Firmicutes and Verrucomicrobia, present at much lower abundance. Only 1 OTU was shared by the bacterial communities of both upstream rivers. UniFrac metric analysis has demonstrated 


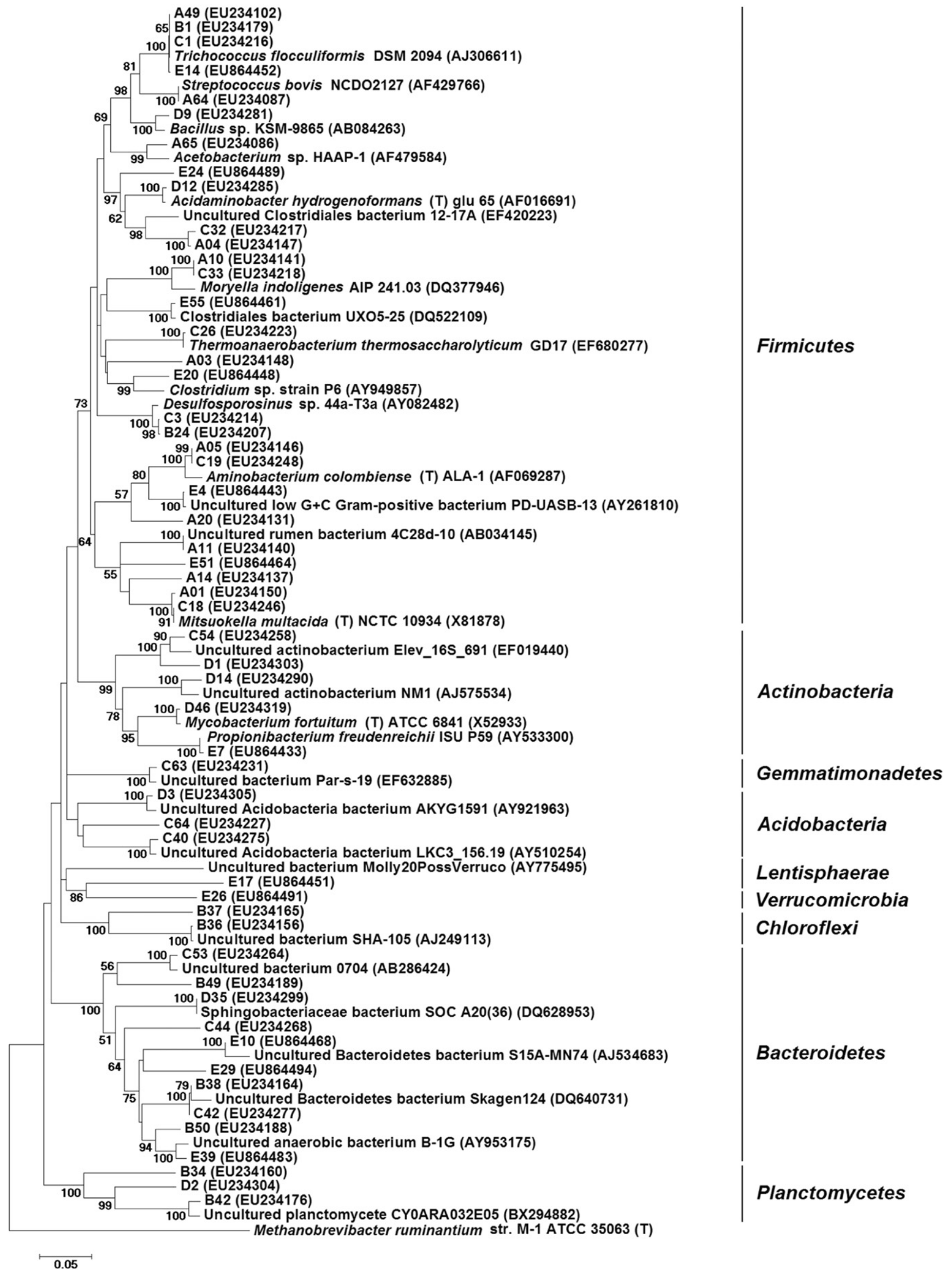

Fig. 3 - Phylogenetic relationships of representative bacterial 16S rRNA gene sequences within the other phyla from clone libraries of this study determined by the neighbor-joining method. Bootstrap values of $>50 \%$ (obtained with 1000 resamplings) are shown at nodes. The scale bar indicates 0.05 nucleotide substitution per site. 


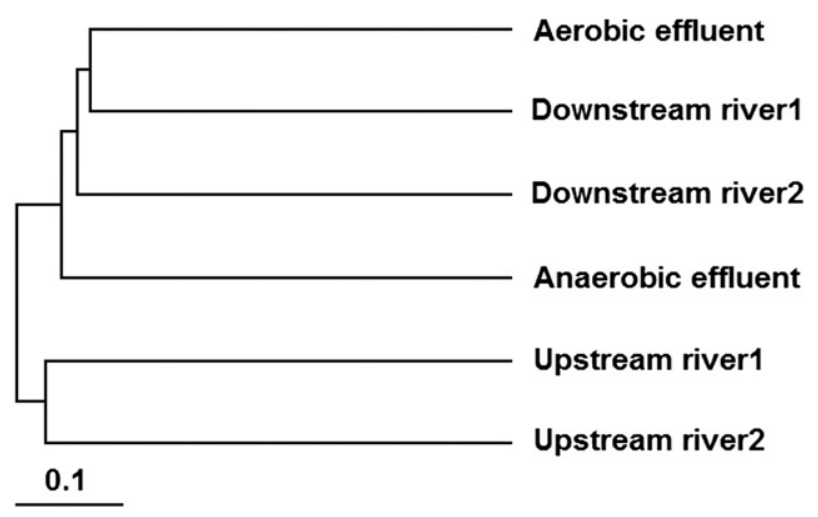

Fig. 4 - Bacterial clone libraries clustering using UPGMA method to UniFrac metric based on all 16S rRNA gene sequences from the upstream and downstream clone libraries of the two rivers 1 and 2 individually receiving treated penicillin $\mathrm{G}$ and oxytetracycline production wastewater, as well as the anaerobic and the aerobic effluent clone libraries of penicillin $\mathrm{G}$ production wastewater.

that both bacterial community compositions in the upstream rivers were distinctly different from the remaining of the antibiotic containing aquatic environments (Fig. 4). PCoA analysis also revealed the similar results (data not shown).

Comparably higher richness and evenness indexes of the clone libraries derived from the aerobic effluent of the WWTP and the downstream river receiving penicillin $G$ production wastewater were observed than those from the anaerobic effluent and the reference upstream river (Table 2), indicating that the bacterial communities in the aerobic effluent and the penicillin $\mathrm{G}$ polluted downstream river were more diverse. Meanwhile, the diversity of the clone library for the oxytetracycline containing downstream river was similar with that of the upstream river. It thus seems that the antibiotic stresses had not obviously reduced the diversity of bacterial community in aquatic environments. This result was accordant with that obtained before, in which phospholipid fatty acid numbers even increased in ciprofloxacin-treated microcosms (Córdova-Kreylos and Scow, 2007), while different from several recent studies on human gut microbiome which showed that the diversity normally decreased significantly with the treatment of antibiotics (Antonopoulos et al., 2009; Rea et al., 2011). The comparably short exposure time of human gut microbiome should be the major reason for the significant reduce of bacterial diversity. It should be noted that as rarefaction curves of all clone libraries in this study did not reach saturation (data not shown), the clone number for each sample was still not sufficient and may affect the indices values.

\section{Discussions}

In this study, Deltaproteobacteria, Epsilonproteobacteria, Clostridia and Bacilli have been found abundant in all antibiotic containing environments. It has been reported that Deltaproteobacteria and Firmicutes were commonly abundant in the anaerobic wastewater treatment systems, with the clone percentages varied among different researches (Godon et al., 1997). Penicillin G production wastewater of this study was treated with a combination of anaerobic and aerobic processes. It is thus possible that the presence of Deltaproteobacteria, Clostridia and Bacilli in the aerobic effluent as well as the corresponding downstream river was related with the release from the anaerobic reactor. However, Epsilonproteobacteria, which is comparably uncommon in the anaerobic treatment systems reported previously (Godon et al., 1997), was the dominant Proteobacteria and accounted for $14.3 \%$ of the total clone number of the bacterial library for the anaerobic effluent. Meanwhile, many previous investigations have demonstrated that the phylum Proteobacteria was generally dominant in the aerobic reactors of WWTPs with Betaproteobacteria being the most frequently observed, and the phyla Bacteroidetes and Actinobacteria were frequently retrieved (Wagner and Loy, 2002). Then Alphaproteobacteria, Betaproteobacteria, Actinobacteria, Acidobacterium and Bacteroidetes were reported to account for the major proportion of the bacterial community in freshwater (Hugenholtz et al., 1998). Furthermore, the clones grouped in Deltaproteobacteria, Clostridia and Bacilli have totally accounted for $37.7 \%$ of the clone number of the library for the oxytetracycline containing downstream river, while no anaerobic treatment was adopted for the oxytetracycline wastewater of this study. Thus, the

Table 2 - Coverage and diversity indexes of bacterial 16S rRNA gene clone libraries for the upstream and downstream of the two rivers individually receiving treated penicillin $\mathbf{G}$ and oxytetracycline production wastewater, as well as the anaerobic and the aerobic effluent of penicillin $\mathbf{G}$ production wastewater.

\begin{tabular}{|c|c|c|c|c|c|c|c|}
\hline Sample & No. of clones & No. of OTUs & $\mathrm{S}_{\text {Chao1 }}$ & $\mathrm{S}_{\mathrm{ACE}}$ & Shannon index & Evenness index & $\%$ Coverage \\
\hline Upstream river $1^{\mathrm{a}}$ & 75 & 23 & 38 & 33.87 & 2.82 & 0.899 & 86.7 \\
\hline Upstream river $2^{b}$ & 72 & 39 & 81.8 & 75.3 & 3.36 & 0.917 & 65.3 \\
\hline Downstream river $1^{a}$ & 82 & 45 & 85.6 & 118.82 & 3.52 & 0.925 & 64.6 \\
\hline Downstream river $2^{\mathrm{b}}$ & 77 & 39 & 76.5 & 87.3 & 3.32 & 0.906 & 67.5 \\
\hline Anaerobic effluent & 77 & 26 & 32.88 & 38.88 & 2.83 & 0.869 & 85.7 \\
\hline Aerobic effluent & 81 & 43 & 116.5 & 118.84 & 3.5 & 0.931 & 63 \\
\hline
\end{tabular}

a The river1 received treated penicillin $G$ production wastewater.

b The river 2 received treated oxytetracycline production wastewater. 
unexpectedly high abundance of the bacterial groups including Deltaproteobacteria, Epsilonproteobacteria, Clostridia and Bacilli appeared in the aerobic effluent and both downstream rivers (the sampling sites generally $20 \mathrm{~km}$ away from the discharge points of wastewater) could not be only attributed to the release from the anaerobic treatment process. Furthermore, the abundance of these bacterial groups might be resulted from both the antibiotics and the co-existing pollutants in wastewater. However, the impacts of antibiotics should be much larger due to their strong bacteriostatic effects. By using molecular methods, several bacterial genera such as Clostridium spp., Eubacterium spp., Streptococcus spp. and Lactobacillus spp. belonging to the classes Clostridia and Bacilli in Firmicutes have been found sometimes still dominant in the human and poultry gut after feeding with antibiotics, together with Bacteroides spp. in Bacteroidetes (Knarreborg et al., 2002; Young and Schmidt, 2004; Jernberg et al., 2005). Antonopoulos et al. and Rea et al. have found that Proteobacteria is particularly enriched in human gut microbiome with the treatment of antibiotics (Antonopoulos et al., 2009; Rea et al., 2011). Lawrence et al. have observed a significant reduction in the abundance of Betaproteobacteria and Gammaproteobacteria in river biofilm communities exposed to a broadspectrum antimicrobial chlorhexidine using fluorescent in situ hybridization (Lawrence et al., 2008), whereas no more information has been provided about the other bacteria groups in their research. Then in the study of Córdova-Kreylos and Scow (2007), sulfate-reducing bacteria belonged to Deltaproteobacteria including Desulfovibrio, Desulfobacter and Desulfobulbus were obviously favored by ciprofloxacin in the sedimental microbial communities. These previous reports have partially confirmed the specific association between the bacterial groups Deltaproteobacteria, Epsilonproteobacteria, Clostridia and Bacilli and antibiotic containing environments.

It still need be noted that the penicillin $G$ is grouped into $\beta$ lactam antibiotics and mainly active against Gram-positive bacteria by acting on bacterial cell wall, while oxytetracycline is a broad-spectrum antibiotic belonging to tetracyclines and inhibits bacterial protein synthesis by binding to the $30 \mathrm{~S}$ ribosomal subunit (Fluit et al., 2001). Several human infection cases caused by sulfate-reducing bacteria belonging to Deltaproteobacteria have been reported, and all of these sulfate-reducing strains had shown co-resistance to multiple antibiotics belonged to different classes (Pitcher et al., 1994; McDougall et al., 1997). Sulfate-reducing bacteria were also not affected by the administration of several different antibiotics in rats (Ohge et al., 2003). Several Arcobacter spp. belonging to Epsilonproteobacteria related to human infections had often been described to confer multi-drug resistance (Fera et al., 2003). In the classes Clostridia and Bacilli, tetracycline resistance gene tet(W) was first identified in one M. multacida isolate (Scott et al., 2000). Some isolates of T. flocculiformis in these classes had shown multiple antibiotic resistance abilities in our previous research (Li et al., 2009), and Streptococcus bovis has displayed multiple antibiotic resistance to several antibiotics (Teng et al., 2001), together with Clostridium spp. strains (Rood et al., 1978). The other bacterial genera in Clostridia and Bacilli including Aminobacterium, Desulfosporosinus, Anaerovorax, Acetobacterium, Thermoanaerobacterium, Ruminococcus, Dialister and Mogibacterium of this study are phylogenetically closely related to intestinal bacterial groups including Clostridium, Eubacterium, Streptococcus and Lactobacillus, which were sometimes still dominant in the gut after feeding the antibiotics (Knarreborg et al., 2002; Young and Schmidt, 2004; Jernberg et al., 2005), suggesting that these bacterial genera of this study possibly shared similar antibiotic resistance mechanisms with those intestinal bacterial groups.

Several antibiotic resistance mechanisms have been described for bacteria, including antibiotic resistance genes which encode antibiotic modifying or inactivating enzymes and usually target one antibiotic class specifically, mutations of antibiotic target sites in bacterial cells, and efflux pump systems locating in bacterial cell membranes and mainly accounting for multi-drug resistance. The occurrence of the specific bacterial groups including Deltaproteobacteria, Epsilonproteobacteria, Clostridia and Bacilli in different antibiotics containing environments suggested that some kind of intrinsic resistance mechanisms might account for the widespread of these groups.

\section{Conclusions}

Several bacterial groups including Deltaproteobacteria, Epsilonproteobacteria, Clostridia and Bacilli have been suggested to be specifically associated with antibiotic containing aquatic environments, many of which have not been recovered in previous antibiotic resistance researches using culture-based analysis.

\section{Acknowledgments}

This work was financially supported by the Ministry of Science and Technology of China (2006DFA91870) and the National Natural Science Foundation of China (20877085 and 50525824).

\section{R E F E R E N C E S}

Altschul, F.S., Madden, T.L., Schäffer, A.A., Zhang, J., Zhang, Z., Miller, W., Lipman, D.J., 1997. Gapped BLAST and PSI-BLAST: a new generation of protein database search programs. Nucleic Acids Research 25, 3389-3402.

Antonopoulos, D.A., Huse, S.M., Morrison, H.G., Schmidt, T.M., Sogin, M.L., Young, V.B., 2009. Reproducible community dynamics of the gastrointestinal microbiota following antibiotic perturbation. Infection and Immunity 77 , 2367-2375.

Clinical and Laboratory Standards Institute, 2003. Methods for Dilution Antimicrobial Susceptibility Tests for Bacteria that Grow Aerobically. Approved standard M7-A6. Clinical and Laboratory Standards Institute, Wayne, PA, USA.

Cole, J.R., Chai, B., Farris, R.J., Wang, Q., Kulam-SyedMohideen, A.S., McGarrell, D.M., Bandela, A.M., 2007. The ribosomal database project (RDP-II): introducing my RDP space and quality controlled public data. Nucleic Acids Research 35, D169-D172.

Colwell, R.K., 2005. EstimateS: Statistical Estimation of Species Richness and Shared Species from Samples. Version 8.0. 
User's Guide and application published at: http://purl.oclc.org/ estimates.

Córdova-Kreylos, A.L., Scow, K.M., 2007. Effects of ciprofloxacin on salt marsh sediment microbial communities. The ISME Journal 1, 585-595.

Crump, B.C., Armbrust, E.V., Baross, J.A., 1999. Phylogenetic analysis of particle-attached and free-living bacterial communities in the Columbia River, its estuary, and the adjacent coastal ocean. Applied and Environmental Microbiology 65, 3192-3204.

D'Costa, V.M., McGram, K.M., Hughes, D.W., Wright, G.D., 2006. Sampling the antibiotic resistome. Science 311, 374-377.

Fera, M.T., Maugeri, T.L., Giannone, M., Gugliandolo, C., La Camera, E., Blandino, G., Carbone, M., 2003. In vitro susceptibility of Arcobacter butzleri and Arcobacter cryaerophilus to different antimicrobial agents. International Journal of Antimicrobial Agents 21, 488-491.

Fluit, A.D.C., Visser, M.R., Schmitz, F.-J., 2001. Molecular detection of antimicrobial resistance. Clinical Microbiology Reviews 14, 836-871.

Godon, J.-J., Zumstein, E., Dabert, P., Habouzit, F., Moletta, R., 1997. Molecular microbial diversity of an anaerobic digestor as determined by small-subunit rDNA sequence analysis. Applied and Environmental Microbiology 63, 2802-2813.

Hall, T.A., 1999. BioEdit: a user-friendly biological sequence alignment editor and analysis program for Windows 95/98/NT. Nucleic Acids Symposium Series 41, 95-98.

Hamelin, K., Bruant, G., El-Shaarawi, A., Hill, S., Edge, T.A., Fairbrother, J., et al., 2007. Occurrence of virulence and antimicrobial resistance genes in Escherichia coli isolates from different aquatic ecosystems within the St. Clair river and Detroit river areas. Applied and Environmental Microbiology 73, 477-484.

Huddleston, J.R., Zak, J.C., Jeter, R.M., 2006. Antimicrobial susceptibilities of Aeromonas spp. isolated from environmental sources. Applied and Environmental Microbiology 72, 7036-7042.

Hugenholtz, P., Goebel, B.M., Pace, N.R., 1998. Impact of cultureindependent studies on the emerging phylogenetic view of bacterial diversity. The Journal of Bacteriology 180, 4765-4774.

Jernberg, C., Sullivan, Å, Edlund, C., Jansson, J.K., 2005. Monitoring of antibiotic-induced alterations in the human intestinal microflora and detection of probiotic strains by use of terminal restriction fragment length polymorphism. Applied and Environmental Microbiology 71, 501-506.

Jindal, A., Kocherginskaya, S., Mehboob, A., Robert, M., Mackie, R. I., Raskin, L., Zilles, J.L., 2006. Antimicrobial use and resistance in swine waste treatment systems. Applied and Environmental Microbiology 72, 7813-7820.

Knarreborg, A., Simon, M.A., Engberg, R.M., Jensen, B.B., Tannock, G.W., 2002. Effects of dietary fat source and subtherapeutic levels of antibiotic on the bacterial community in the ileum of broiler chickens at various ages. Applied and Environmental Microbiology 68, 5918-5924.

Kolpin, D.W., Furlong, E.T., Meyer, M.T., Thurman, E.M., Zaugg, S D., Barber, L.B., et al., 2002. Pharmaceuticals, hormones, and other organic wastewater contaminants in US streams, 1999-2000: a national reconnaissance. Environmental Science and Technology 36, 1202-1211.

Kumar, S., Tamura, K., Nei, M., 2004. MEGA3: Integrated software for molecular evolutionary genetics analysis and sequence alignment. Briefings in Bioinformatics 5, 150-163.

Lane, D.J., 1991. 16S/23S rRNA sequencing. In: Stackebrandt, E., Goodfellow, M. (Eds.), Nucleic Acid Techniques in Bacterial Systematics. John Wiley, Chichester, United Kingdom, pp. 115-175.
Lawrence, J.R., Zhu, B., Swerhone, G.D.W., Topp, E., Roy, J., Wassenaar, L.I., Rema, T., Korber, D.R., 2008. Community-level assessment of the effects of the broad-spectrum antimicrobial chlorhexidine on the outcome of river microbial biofilm development. Applied and Environmental Microbiology 74, 3541-3550.

Li, D., Yang, M., Hu, J., Zhang, J., Liu, R., Gu, X., Zhang, Y., Wang, Z. , 2009. Antibiotic resistance profile in environmental bacteria isolated from penicillin production wastewater treatment plant and the receiving river. Environmental Microbiology 11, 1506-1517.

Li, D., Yang, M., Hu, J., Ren, L., Zhang, Y., Li, K., 2008 a. Determination and fate of oxytetracycline and related compounds in oxytetracycline production wastewater and the receiving river. Environmental Toxicology and Chemistry 27, 80-86.

Li, D., Yang, M., Hu, J., Zhang, Y., Chang, H., Jin, F., 2008b. Determination of penicillin $\mathrm{G}$ and its degradation products in a penicillin production wastewater treatment plant and the receiving river. Water Research 42, 307-317.

Lozupone, C., Knight, R., 2005. UniFrac: a new phylogenetic method for comparing microbial communities. Applied and Environmental Microbiology 71, 8228-8235.

Martínez, J.L., 2008. Antibiotics and antibiotic resistance genes in natural environments. Science 321, 365-367.

Martínez, J.L., Baquero, F., Andersson, D.I., 2007. Predicting antibiotic resistance. Nature Reviews Microbiology 5, 958-965.

McDougall, R., Robson, J., Paterson, D., Tee, W., 1997. Bacteremia caused by a recently described novel Desulfovibrio species. Journal of Clinical Microbiology 35, 1805-1808.

Messi, P., Guerrieri, E., Bondi, M., 2005. Antibiotic resistance and antibacterial activity in heterotrophic bacteria of mineral water origin. Science of the Total Environment 346, 213-219.

Miranda, C.D., Zemelman, R., 2002. Antimicrobial multiresistance in bacteria isolated from freshwater Chilean salmon farms. Science of the Total Environment 293, 207-218.

Ohge, H., Furne, J.K., Springfield, J., Sueda, T., Madoff, R.D., Levitt, M.D., 2003. The effect of antibiotics and bismuth on fecal hydrogen sulfide and sulfatereducing bacteria in the rat. FEMS Microbiology Letters 228, 137-142.

Pitcher, M.C.L., Gibson, G.R., Neale, G., Cummings, J.H., 1994. Gentamicin kills multiple drug-resistant sulfate-reducing bacteria in patients with ulcerative colitis. Gastroenterology 106, A753.

Rea, M.C., Dobson, A., O’Sullivan, O., Crispie, F., Fouhy, F., Cotter, P.D., Shanahan, F., Kiely, B., Hill, C., Ross, R.P., 2011. Effect of broad- and narrow-spectrum antimicrobials on Clostridium difficile and microbial diversity in a model of the distal colon. Proceedings of the National Academy of Sciences of the United States of America 108 (Suppl. 1), 4639-4644.

Riesenfeld, C.S., Goodman, R.M., Handelsman, J., 2004. Uncultured soil bacteria are a reservoir of new antibiotic resistance genes. Environmental Microbiology 6, 981-989.

Rood, J.I., Maher, E.A., Somers, E.B., Campos, E., Duncan, C.L., 1978. Isolation and characterization of multiply antibioticresistant Clostridium perfringens strains from porcine feces. Antimicrobial Agents and Chemotherapy 13, 871-880.

Scheff, G., Salcher, O., Lingens, F., 1984. Trichococcus flocculiformis gen. nov. sp. nov. A new gram-positive filamentous bacterium isolated from bulking sludge. Applied Microbiology and Biotechnology 19, 114-119.

Schloss, P.D., Handelsman, J., 2005. Introducing DOTUR, a computer program for defining operational taxonomic units and estimating species richness. Applied and Environmental Microbiology 71, 1501-1506.

Scott, K.P., Melville, C.M., Barbosa, T.M., Flint, H.J., 2000. Occurrence of the new tetracycline resistance gene tet(W) in 
bacteria from the human gut. Antimicrobial Agents and Chemotherapy 44, 775-777.

Sommer, M.O.A., Dantas, G., Church, G.M., 2009. Functional characterization of the antibiotic resistance reservoir in the human microflora. Science 325, 1128-1131.

Teng, L.-J., Hsueh, P.-R., Ho, S.-W., Luh, K.-T., 2001. High prevalence of inducible erythromycin resistance among Streptococcus bovis isolates in Taiwan. Antimicrobial Agents and Chemotherapy 45, 3362-3365.

Thomas, C.M., Nielsen, K.M., 2005. Mechanisms of, and barriers to, horizontal gene transfer between bacteria. Nature Reviews Microbiology 3, 711-721.

Thompson, J.D., Gibson, T.J., Plewniak, F., Jeanmougin, F., Higgins, D.G., 1997. The ClustalX windows interface: flexible strategies for multiple sequence alignment aided by quality analysis tools. Nucleic Acids Research 25, 4876-4882.

Wagner, M., Loy, A., 2002. Bacterial community composition and function in sewage treatment systems. Current Opinion in Biotechnology 13, 218-227.

Wittwer, M., Keller, J., Wassenaar, T.M., Stephan, R., Howald, D., Regula, G., Bissig-Choisat, B., 2005. Genetic diversity and antibiotic resistance patterns in a Campylobacter population isolated from poultry farms in Switzerland. Applied and Environmental Microbiology 71, 2840-2847.

Young, V.B., Schmidt, T.M., 2004. Antibiotic-associated diarrhea accompanied by large-scale alterations in the composition of the fecal microbiota. Journal of Clinical Microbiology 42, 1203-1206. 